40. Lomax M. The eternal new year. Theosophical Review 1905; 36: 213.

41. Lomax M. The meaning of Maya. Theosophical Review 1907; 40: 306.

42. Anon. Pathology of insanity. British Medical Journal 1921; 2: 616.

43. Faith healing at mental hospitals. Evening Star, 6 June 1923, p.1.

44. Day G. Rivers of Damascus: the story of a modern miracle in spiritual healing. London: Rider and Co, 1939.

45. Anon. Spiritual healing. Nature 1924; 113: 73-74.

46. Boyle $\mathrm{H}$. The ideal clinic for the treatment of nervous and borderland cases. Proceedings of the Royal Society of Medicine 1922; 15(Sect Psych): 39-49.

47. Cobb Inquiry. Appendix 1: Witnesses heard in public, 1922. MH58/222, TNA.

48. Scrutator. Asylum whitewash. Truth, 16 August 1922, pp.274-276.
49. Lomax M. The asylum inquiry. Truth, 9 August 1922, pp.235-236.

50. Scrutator. A move towards lunacy reform. Truth, 16 April 1924, p.728.

51. Scrutator. Dr Lomax's revelations: what is to follow? Truth, 10 August 1921, p.235.

52. Scrutator. The truth about public asylums. Dr Lomax's revelations. Truth, 3 August 1921, p.197.

53. Report of the Royal Commission on lunacy and mental disorder. London: HMSO, 1926.

54. Illness of Dr M. Lomax. Mid Sussex Times, 13 April 1926, p.8.

55. Montagu Lomax, M.R.C.S.Eng., L.R.C.P.Edin. Lancet, 25 March 1933, p.668.

56. Hilton C. Improving psychiatric care for older people: Barbara Robb's campaign 1965-1975. London: Palgrave Macmillan, 2017, p.237.

\title{
Dr Hetty Brenda Ockrim (1919-2007) and her medical legacy
}

\section{Kenneth Collins}

\begin{abstract}
Dr Hetty Ockrim was a general practitioner in an inner-city Glasgow district for 43 years, before retiring in 1989. This paper looks at her career and her legacy through the pioneering oral history study she undertook, on retirement, with former patients, and the 'Letters to No-one' written at the time of her retirement but only discovered at the time of her death.
\end{abstract}

\section{Keywords}

General practice, women in medicine, domiciliary midwifery

\section{Introduction}

Hetty was born in Glasgow, on 23 August 1919. Her family had arrived there around 1890, fleeing the hardships of life as Jews in Russian Poland. As a teenager, she had already decided that she wanted a career in medicine. Her younger sisters were to become accountants while her younger brother Jack eventually gave up his medical studies because of chronic health problems. The major movement of Jews into medicine in Scotland especially with the rise of the first generation to be born in Scotland was essentially a male phenomenon. ${ }^{1}$ Even by 1938 , when Hetty was ready to apply for a University place there were very few Jewish women in medicine in Scotland. Her businessman father felt that the medical profession was not appropriate for a Jewish girl and insisted that she choose a different course. She was accepted to study a science course at the Glasgow University knowing that it shared a similar first year with medicine.

At the end of the first year, she applied to the Medical Faculty, without telling her parents, and was accepted to enter the second year of the medical course. They quickly came to accept her career choice and supported her

Department of Medical History, University of Glasgow, UK

\section{Corresponding author:}

Kenneth Collins, Department of Medical History, University of Glasgow, Lilybank House, Glasgow GI2 8QQ, UK.

Email: drkcollins@gmail.com 
through her studies. It was obvious in later years just how proud her parents were of her care and compassion, and her remarkable energy which informed all that she did. By the time Hetty entered the medical course, there was a significant group of female medical students but women were still a minority in the medical profession and most of the population would never have encountered one. Indeed, the proportion of women at the University of Glasgow had not changed in years after the First World War remaining just over $10 \% .^{2}$

The experience of being thwarted in her first year at university from embarking on the course of her choice and the action she took to put her career on track gave her a rare understanding of people trying to follow their dreams. People frequently commented on her ability to counsel people at the cross-roads of life. Her medical studies were pursued enthusiastically, and she graduated in 1943, followed by house jobs at the Glasgow Royal Infirmary. Her plans were to go into obstetrics and gynaecology, but she was sympathetic to the plight of local doctors, unable to arrange locum cover for holiday breaks during the war as so many doctors were serving with the British Army in different locations around the globe.

She spent some months working in Blantyre, then a small mining town not far from Glasgow. It was a rapid introduction to life in the community. There were mining accidents and the full range of illnesses to treat in wartime conditions. She coped well with the work and a reference from the practice doctor, Dr Arthur Gordon, related that:

Dr. Ockrim had the difficulty of being the first lady doctor in the practice and the way in which she not only overcame certain prejudices but won over these people, is in itself a testament to her abilities (Letter on file with author).

She moved on to positions of senior house officer, and then registrar in Obstetrics and Gynaecology, working at the Elsie Inglis Hospital in Edinburgh. Hetty then returned to Glasgow with posts at the Royal Infirmary and the Royal Samaritan Hospital for Women. Dr Donald McIntyre, University Lecturer in Gynaecology and Visiting Surgeon at the Royal Samaritan Hospital, wrote on 15 October 1945, that:

.... she was unsparing in the energy she devotes to her work and she is held in the highest esteem by both parents and nursing staff.... and has proved herself a safe and competent anaesthetist (Letter on file with author).

This was a skill she would employ in the early post-war years in conducting more complicated home deliveries. However, her plans for specialisation suddenly changed after meeting a former major in the Royal Army Medical Corps, David Collins, who was to become her husband. After graduation in 1939, he worked first at the Blawarthill
Hospital in Clydebank and was there during the devastating Clydebank Blitz, when massive air-raids by the Luftwaffe took place on two successive nights in March 1941. The town suffered extensive destruction. Tens of thousands were made homeless and there were 1200 deaths with around a thousand seriously injured. There was extensive industrial damage to Clydebank's shipbuilding and the housing loss led to mass evacuation. This was followed by a year as a Medical Recruitment Officer after which he joined the British Army invasion of North Africa at the end of 1942 working as a field general practitioner and he was in an army unit which followed the invasion of Italy, before returning to Glasgow at the end of 1945.

\section{Entering general practice}

Hetty and David decided to enter general practice together and they bought a practice in the Ibrox area of Glasgow in June 1946. The core of the practice population is the traditional Scottish working class with a significant influx, in the decades before 1990, from Pakistan and India. In 1946, the working population was substantially based around heavy engineering and the nearby docks. The health demands of the population in the early years of the National Health Service (NHS) were very onerous. Today, areas of the practice maintain an air of prosperity while patients at the edge of the wide catchment area represent a mix of post-war council housing as well as leafy suburbs. With its good transport links and affordable housing, the immediate area around the surgery is popular with students and young professionals while parts of the neighbourhood suffer from severe urban blight and problems with drug addiction.

Hetty's consultant at the Royal Samaritan Hospital for Women was Dr Albert Sharman (1903-1970), one of the most distinguished gynaecologists of his generation. ${ }^{3}$ Sharman had a friend in Ibrox, Dr Stevan George, who was planning to leave Britain before the start of the NHS. Sharman arranged for Dr George to meet with Hetty and David and by February 1946, the practice had been bought and David was working at 2 Cessnock Street. There was a short period of overlap as Dr George finished his work and introduced the new doctor to his patients, and David was joined just a few months later by Hetty. They were married on 12 November 1946. There was family support to help them buy the practice, as was the custom in pre-NHS days and efforts were made to augment the practice size by recruiting friends and family to the patient list.

With her training in obstetrics, she threw herself enthusiastically into general practice maternity care delivery in addition to the routine of dozens of patient contacts in the open-access surgeries which ran mornings and afternoons through the week. The time constraints and unsocial hours of her obstetric practice led her to prioritise her 
surgery time and she immediately introduced special clinics for child health and ante- and post-natal care. She was quick to offer her patients cervical cytology and was one of the earliest users of hospital diagnostic services when these became available in the 1960s. She supported the development of new services and facilities which transformed the practice in her last working years and continued to practice full time after the prolonged illness of her husband following a stroke in 1978.

General practice had been a popular career choice for women for more than 30 years. ${ }^{4}$ There were many young doctors returning home after the war, and Army doctors who had seen active wartime service did not easily find a practice in 1946. David had the advantage that, as he had joined up early and had worked with casualties during the Blitz, he was among the first to be demobbed. There were memories of demobbed doctors after the First World War scrambling for practices and he would have felt that there was no time to be lost. ${ }^{5}$ When David and Hetty bought the practice, they took over the large ground-floor flat at the corner of Cessnock Street and Paisley Road West, situated directly across the road from the Cessnock Street subway station. They retained the resident caretaker who occupied some ground-floor and basement rooms but as practice conditions demanded additional space for office staff and extra doctors, the practice gradually filled the whole area.

After the NHS began, the practice population regularly numbered around 9500 and was normally served by four doctors. A third partner, Dr Ian Russell, was appointed in 1949 , in addition to the regular presence of a practice assistant. The practice continued with four doctors until the 1980s. ${ }^{6}$ Their son, Kenneth, joined the practice as an assistant in November 1976 and became a partner in the following April. An additional partner was appointed in 1986 just before the practice moved to the purpose-built Midlock Medical Centre nearby.

Hetty faced the prospect of retirement with some trepidation, and we discussed some options which would ease the transition from the active and bustling life of an innercity general practitioner into more traditional retirement pursuits. It had become the norm for many general practitioners, facing an increasingly intrusive NHS management bureaucracy to retire around the age of 60 years but Hetty was not ready to leave her work at that stage, although she did stop her obstetrics work in the General Practitioner Unit at the Southern General Hospital. She continued to practice up to the month after her 70th birthday and it was only the discovery of a collection of letters in her desk, in a brown enveloped marked 'Letters to No-one' 18 years after her retirement that gave an insight into her mood and feeling of that time ('Letters to No-one' on file with author). She never gave any indication during her lifetime of the existence of these letters and the contents were likely very different from what might have been written were she have been asked to share her feelings about retirement.

In the first letter, dated April 1989, she described her life in practice as 'rushing and running' and wondered what was to be when this stopped. She worried about the patients she had cared for over the past four decades whose personal problems, even more than their strictly medical ones, affected her deeply. Focussed firmly on the present she saw little value in celebrating retirement but contented herself that she had established a thriving medical practice, touching the lives of many people, overwhelmed by their affection and involved in all aspects of their care.

Retirement can mark a difficult transition from a respected and often hectic professional life to an uncertain and very different future stretching out for many years. It can also give the opportunity for retrospection and inner reflection:

If my late husband had not been discharged from the army at that particular time, I should not have been in general practice and would have missed all this. I do not think that any branch of medicine could give the same sort of satisfaction or relationship.

Is it a celebration? I have prepared myself that at the age of three score and ten I should retire. It seems now the right decision but when shall I know? All my life I have rushed and run and when the running and rushing stops, what then? This is what worries me. I am not used to sitting about but neither am I trained for anything else and physically I do not feel up to starting something new. And what of my temperament - intolerant in a word. However, my decision is resolute.

Her description of herself as 'intolerant' is interesting. She was certainly intolerant of bureaucracy and health service delays, of alcoholism and malingering but tolerant of all she met and her ability to care was legendary. This is reflected in many statements from interviews with former patients. Her care was not just a matter of paying attention to cases in a clinic but a concern that persisted all through her working life and this concern was as strong at her retiral as it had been throughout her working life. She wrote:

At work I am upset by the distressing stories of hardship among young and old. I have compiled several lists of names of people with problems - each of which could fill a book. What of GD - his life is a nightmare - if anyone had a nightmare so bad? What of MC, age 89 whose son, a doctor, died at thirty years of age, afraid that her money will run out - what then? What of SE, unmarried with three handicapped children and can't cope? 
Finally, came her concern about keeping up to date with medical developments, not to mention the frequent periods of re-organisation experienced by NHS primary care.

The pressures of medicine today are too great. The new and complex drugs with their interactions and side-effects, one must be alert and quickly reactive. I do not think I could continue to be up to my own expected standard and target and give of my best. Although, I do think, at the moment, I am no worse than anyone else - am I being complacent? I did not want [a retirement gift of] a painting [but] the office staff insist. Do they think it is a celebration - my going?

The mood changes by the time of the second letter, in July 1989:

The die is cast. My resignation has been tendered and a notice of my retiral has been posted. The sad part of me is that I am going and will lose contact with all those who have been part of my life for 43 years. The glad part is the emotional sentiments of my patients and friends, because that is what these people have become ... The over 70s are sad and some are tearful as they speak of their memories of their parents, children and grandchildren. In some families I am on my fifth generation. The over 50s say I deserve my retiral and wish me a long retiral to enjoy whatever I choose to do. The younger are also reminiscing and I am surprised at those who kiss and hope that we shall meet again. The children will miss me - perhaps my successors will be happy to display their school photographs, which they love to bring, their paintings and enjoy a little sweet which they know I keep for them in the top drawer.

In some ways, the final letter, written on 5 October 1989, just after finishing work and clearing her desk on the last day of September, is quite surprising given the detailed introspection which preceded it. The date of retirement was timed to lead into a pre-arranged holiday so that the new life would follow an overseas trip and not a regular workday. On her last day at work, there was a retiral party which she described in the October letter as "probably one of the outstanding days of my life: a party arranged in the surgery by the staff'.

\section{The oral history project}

More than anything else it would seem that the emotions generated by the retirement party and the cards, messages and small gifts from many dozens of patients produced an awareness that an oral history study was a fitting way to perpetuate her legacy and indicate the relationships which develop over the generations of caring. In June she had spoken of five generations: the new study would bring this to life in remarkable ways. The oral history let her patients comment on what was important to them in their encounter with health care in the Ibrox and Govan areas of Glasgow. This oral history study deserves a wide audience - especially for health care professionals and the consumers of their services.

Through the words of her former patients, we encounter how these aims worked out in practice as they accepted her as a practitioner describing her skills of empathy, judgement and resilience. In the first days in the practice, when the attention of the doctor counted for as much as the prescribed medication, there was a sense of appreciation which always remained with the patient. Mercer et al. noted that GP Principals in Scotland showed continuing wide-spread support for holistic primary care, and frustration at a system which appears to discourage such a priority. ${ }^{7}$ Their study shows that the quality agenda in general practice has focussed more on access and bio-medical aspects of care than on relationship between patient and doctor. Hetty's oral history interviews show the vital importance of this relationship and give an insight into how this played out in her former practice.

The Project was supported by Wellcome Trust funding and involved the interviewing of some 75 former patients and some of the employed and attached staff between October 1989 and March 1992. Patients were identified from a wide range of social, employment and ethnic backgrounds reflecting the diverse nature of the local community. There was a special emphasis on Dr Ockrim's extensive experience of community obstetrics with home deliveries in the early years giving way to births in nursing homes and latterly in a hospital-based general practitioner unit. The study was planned to add to the growing body of material on the history of general medical practice in Britain, through patient narratives as mediated by one of their own family doctors. ${ }^{8}$ It aimed to elicit the health care account of patients in one urban practice and allows for the reconstruction of history in the telling of its story.

Patients were interviewed following a semi-structured interview protocol. The interviews were conducted following a study course at the University of Essex in October 1989, organised by Professor Paul Thomson, one of the pioneers of oral history as a research methodology in the social sciences. ${ }^{9}$ A careful balance of age, occupation, health experiences and ethnic origin was part of the design of the project. It was recognised that there might be tensions involved in history taking given the special relationship between interviewees and the recently retired practitioner but the opportunity to understand the unique focus between patient and doctor meant also that there was much to be gained.

This oral material, a unique account of the doctor patient encounter, illuminates the attitudes of patients to a range of topics as wide as the scope of general practice itself. The interviews, comprising $160 \mathrm{~h}$ of recordings were transcribed during 1992, covering around 3000 pages, but the formal 
study of this rich seam of medical history has only commenced during the past couple of years, although some brief presentations on aspects of the study were made earlier. ${ }^{10}$ The audiotapes and their transcripts are now held by the Scottish Oral History Centre at the University of Strathclyde, with certain restrictions on access.

General practice reflects the interface between clinicians and the community, and this study marks the beginning of an attempt to understand the delivery of medical care in the first decades of the NHS through an encounter between doctor and patient. It reveals many aspects of patient attitudes to care and has a focus on women in practice and the provision of maternity care in the community in the first decades of the NHS. ${ }^{11}$ The interviews covered every branch of medicine, including practice organisation, maternity care, medical and psychiatric conditions, infectious diseases, drug addiction and alcoholism. Here, we can examine briefly just a few of the key topics covered by the project, focussing on Hetty's love of obstetrics.

\section{Patient attitudes}

As people could be seated together for anything up to an hour in the waiting room when there was no appointments system in place, it was an opportunity for patients to exchange views on a variety of subjects, mainly with a practice content.

I used to love - I loved going to the doctor and sitting there. You met such nice people. Like you used to go in and sit and you would reminisce about where you stayed and what your kiddies done. You cannae dae the same now. That [was] an outing for me. (AM11). ${ }^{12}$

They'll maybe give you their life history, you know, from the day they were born till they came to this particular appointment. (SM25)

\section{On Women Doctors}

In the early days of the practice, a priority was increasing the number of patients on the list and there were many who quickly welcomed a female doctor:

I feel I cannae talk to a man. I missed you terrible when you went. Tae me you're no a doctor, tae me you're my friend as well as a doctor. (MC5)

I was with (a male doctor) and he told me I was pregnant, so I came over to your practice because I preferred a lady doctor. (SH12)

However, this was not a universal attitude and certainly in the late 1940s and early 1950s, there remained serious prejudice against women in medicine:
There was Dr George himself, but he had an assistant at one time. She was a lady doctor. The entrenched thought of people those days, nobody wanted to go to the lady doctor and there was always a big queue for Dr George. (B60)

These attitudes clearly persisted after the practice changeover in 1946:

I think in the old days very few people went to see you because you were a lady doctor. My son-in-law always used to go to you, and they would say, 'Look at that jessie sittin' there to go to Dr Ockrim. (27DS)

The following incident, which occurred in the early 1950s, indicates her frustration with these attitudes:

I was sitting with the children in the big waiting room and there was a big queue. So they were all waiting for $\mathrm{Dr}$ Collins at this side, and the next thing Dr Ockrim flares out of her room, stands with her hands on her hips, and says, 'I'm a doctor too, you know - NEXT!' Everyone just sat with their mouths open and there was a few laughs. She was quite right. (JG39)

During the 1970s, there was a significant influx into the neighbourhood of patients from Pakistan and India who had a more conservative attitude to gender issues and who actively sought out a practice with a woman doctor:

...my mum went to Dr Ockrim, because she was a female. It is in our religion. We always went to a female rather than a male doctor. A male always went to a male. (BG57)

Some complex testimony from a patient who suffered physical and sexual abuse from her father described the feelings she had about attending both male and female practitioners, during the 1960s and 1970s:

I used to always have to talk to a man doctor. I don't know. I think I was more dominated by a male. I reckon that's the answer. Mostly, because it's been a male that's dominated you all your life .... You felt that women were just a waste of time. (LE50)

This patient came to consult with Dr Ockrim, seeing a woman in authority with the ability to provide the control that had been lacking in her own life:

Aye, I felt kind of close, but no' close enough to tell you [about the abuse]. There was something powerful about you that I liked. There was a lot of people didnae like you. I used to say to people, 'She's straightforward and she'll tell you to your face what she thinks.' There was just something aboot you. My da' was always with me. 
You used to say to my da' - 'Are you still drinking? Do you not think it's about time you stopped drinking?' You were saying this, and I thought, 'That's great.' .... and I used tae see you stronger than my da'. (LE50)

\section{Obstetric care}

Becoming a general practitioner gave her a new focus for her commitment to all aspects of good maternity care. In the early days of the practice, the news of a 'specialist' in obstetrics working in the community led to an influx of patients and some local general practitioners, nervous about patient expectations about their own abilities, referred their patients to her.

Patients saw many advantages in a home delivery with a family support network around them and attendance by the familiar figure of the family doctor. While general practitioners were expected to be available to patients even during the delivery most local doctors were happy to leave things to the local midwives. It was even common for general practitioners to be credited with a birth but for the actual delivery to be conducted by the midwife. ${ }^{13}$ However, midwives did acknowledge the place for the general practitioner with the appropriate skills. An interviewed midwife, Margaret French, commented:

It's a strange thing when the doctor delivers patients, there's a kind of bond. There's no doubt about it. They feel very secure with their own doctor, I think.

Midwives would often spend many hours with their patients while general practitioners, who had to juggle other commitments, would have to confine their time to a short period of assessment and then return in time for the delivery.

Dr Ockrim was determined to provide the best available care to mothers and babies while working in a cooperative fashion with the community midwives. She campaigned for sub-standard nursing homes to improve or face closure. She had begun her practice in an era, where the traditional unqualified birth assistant, the 'howdie', commonly found in rural areas in Scotland was still operating in Glasgow. ${ }^{14}$ She was prepared to do forceps and breech deliveries, often with the district nurse giving the anaesthetic via an open mask with gauze and ether or chloroform, until measures which required intubation became the required norm. There were many memories of these times. ${ }^{15}$ However, general practitioner involvement in delivering babies steadily fell as ultimately almost all births took place in hospital.

My second baby was born at home. Dr Ockrim, herself, delivered him in the house. I preferred the home delivery; it was a different experience entirely. There was no comparison. The doctor was there the whole time and attended to you. In the hospital you were left quite a lot yourself to get on with it, but at home you had a student, a midwife and the doctor in attendance and everyone couldn't be nicer. (SH12)

Ah wisnae really upset about... because I felt quite safe whenever you came in. I was quite content whenever you came in. I said, 'Well, Dr Ockrim's here, I don't need to worry', and - I don't know - I think the baby would have died that morning if you hadnae delivered her. (MJ29)

\section{St Francis nursing home}

As the number of home deliveries decreased, Hetty did most of her maternity work at the St Francis Nursing Home, near the practice. She cooperated easily with the nuns and midwives at St Francis and there were hospital consultants who were happy to be called there if serious complications occurred. The St Francis Nursing Home had been founded to provide a maternity unit that would uphold Catholic values, deflecting medical pressure on mothers to have terminations or sterilisation on account of foetal handicap or complications of pregnancy. ${ }^{16}$

While Hetty was greatly appreciative of the skills and care of the nuns at St Francis, not all the patients had the same attitude to childbirth in a nursing home with a strong Catholic ethos.

I had the delivery in St Francis. She [Hetty] said, 'You can go to St Frances.' I said, 'I'm not a Catholic.' She said, 'That doesn't make any difference.' [It was] marvellous. (MJ10)

[My wife] had her baby in St Francis. She had a caesarean. You were in attendance at the birth.... and you assisted .... St Francis was very good, apart from all their ringing bells and that... They didn't twist it, you know, [her] not being Catholic which was very good. (JW14)

.... they seemed to attend the Roman Catholics more. (SI18)

With the opening of the GP Unit at the Southern General Hospital, there was the opportunity for the general practitioner to be involved at all stages of the care of their patient, but within a consultant-led obstetrics department with all the specialist back-up that might be needed.

I think it was yourself that delivered my second baby in the GP Unit at the Southern General. I preferred my own doctor to do the delivery because it was more personal. They were with you all through the pregnancy and I think it was nice to have them at the end of it. You felt comfortable. (WE51) 
In time both the hospital GP unit and the maternity department at the St Francis Nursing Home were closed. Hetty eventually found the time required at the GP Unit too much of a conflict with practice requirements and she withdrew from the service around 1980. A final tribute to Hetty appeared in a letter, headed 'Wonderful Woman' to the Editor of The (Glasgow) Herald just 1 day after they had printed an obituary about her:

Dr. Ockrim, as she was known, is a legend in our family, following my successful delivery in June 1962 in the family home in Drumoyne.... Mum still recalls with affection the care she received from this wonderful lady.... Mum is now in her 77th year and shed more than just a few tears on reading the obituary. (Jim and Karen McQueen)

\section{Conclusion}

As a partner in a large medical practice from the summer of 1946, Hetty had to establish herself as a trusted listener, confidant, diagnostician and practitioner. Forty-three years in her medical practice did not dim her enthusiasm for her work or for the ethos of the NHS, which sought from the outset to give quality medicine to the entire population, free of charge at the point of contact. Her marriage and the formation of a GP partnership drew together all these strands in a positive way.

\section{Acknowledgements}

I would like to thank the partners and staff at the Midlock Medical Centre, Glasgow G51 1SL, for their help and support during the oral history programme and especially Sandra Grant who typed the transcripts with great accuracy and attention to the local dialect. Written permissions were obtained from all the interviewees for use of extracts of their testimonies as published and the study obtained the necessary ethical committee approvals.

\section{Declaration of Conflicting Interests}

The author declared the following potential conflicts of interest with respect to the research, authorship and/or publication of this article: Dr Kenneth Collins was a partner in the Cessnock/ Midlock practice from 1977 to 2007 and is the son of the late Drs Hetty B Ockrim and David Collins.

\section{Funding}

The author received no financial support for the research, authorship and/or publication of this article.

\section{ORCID iD}

Kenneth Collins (iD https://orcid.org/0000-0002-6225-5880

\section{References and notes}

1. Collins K. Go and learn: the international story of the Jews and medicine in Scotland 1739-1945. Aberdeen: Aberdeen University Press, 1987, p.86.

2. Carol Dyhouse. No Distinction of Sex? Women in the British Universities 1870-1939. London: UCL Press, 1995, p.249. In 1920-21 there had been 1,122 women at the University of Glasgow out of 4,518 (24.0\%) and by 1934-35 there were 1,149 women out of 4,390 (26.1\%). Figures from Returns of the University Grants Committee.

3. Obituary of Albert Sharman DSc PhD MD FRCS (Glas) FRCOG, BMJ, 1970, p.634.

4. Alexander W. First ladies of medicine. Glasgow: University of Glasgow, 1987, p.49.

5. Moberly Bell E. Storming the Citadel. London: Constable \& Co, 1953, p.171.

6. The average practice list size (per doctor) was 2,206 in Scotland in 1951. Quoted in Anne Digby, the evolution of British general practice 1850-1948. Oxford: Oxford University Press, 1999, p.336.

7. Hasegawa H, Reilly D, Mercer SW, et al. Holism in primary care: the views of Scotland's general practitioners. Primary Health Care Research and Development, 2006; 6: 320-328, doi: https://doi.org/10.1191/1463423605pc248oa. Published online by Cambridge University Press: 31 October 2006.

8. Irvine Loudon, John Horder and Charles Webster. General Practice Under the National Health Service 1948-1977, Oxford: Clarendon Press, 1998. The book, written by medical practitioners and social scientists, provides an invaluable guide to general practice in the first years of the NHS.

9. The importance of oral history has been described in Paul Thompson. The Voice of the Past: Oral History, (Oxford University Press, second edition, 1988); Lynn Abrams' Oral History, second edition, (Routledge, London and New York, 2016); Alessandro Portelli, What Makes Oral History Different? in Robert Perks, Alistair Thomson, editors, The Oral History Reader, second edition, (Routledge, London and New York, 1998).

10. Kenneth Collins. Oral History in an Urban Glasgow Practice, Poster Presentation, Royal College of General Practitioners Conference, Glasgow, October 2009. Oral presentations were also made at conferences in Edinburgh, London, Jerusalem, Halkidiki (Greece) and Auckland (NZ).

11. For the role of oral history and narrative medicine in understanding British general practice and medicine generally, see: Smith G, Nicolson M. Re-expressing the division of British medicine under the NHS: The importance of locality in general practitioners' oral histories, Social Science and Medicine, 64 (4), 2007; Greenhalgh T and Hurwitz B. Narrative Based Medicine: Dialogue and Discourse in Clinical Practice, BMJ Books, London, 1998. Smith G, Bornat J. Oral history, biography, life history: broadening the evidence. British Journal of General Practice, 1999, 49 (446); Bornat J, Perks R, Thompson P and Walmsley J. editors, Oral History, Health and Welfare, (C 2000). There are many studies of Scottish midwifery: see Lindsay Reid, Midwifery in Scotland: A History, Scottish History Press, 
Erskine, 2011 and Lindsay Reid, Scottish Midwives: Twentieth Century Voices, second edition, Black Devon Books, Dunfermline, 2011. For the decline in general practice midwifery see Irvine Loudon and Mark Drury, Some Aspects of Clinical care in General Practice, in Loudon, Horder and Webster, General Practice Under the National Health Service, p.112.

12. Patient names are on file with author. Here they are all represented by code names and numbers.
13. Reid L. Midwifery in Scotland - A History. Erskine: Scottish History Press, 2011, p.24.

14. Howdies were still working in Glasgow as late as 1947. See Lindsay Reid, Midwifery in Scotland, p.24.

15. Comments of Dr. Hetty in interview with Margaret French.

16. Obituary of Dr. Francis O'Reilly, Glasgow Herald, 3/5/1997. His ultimate retirement, coinciding with growing difficulties in finding midwives from the ranks of the St Francis's nuns, saw the end of this era.

\title{
Voltaire and the politicization of medicine and science
}

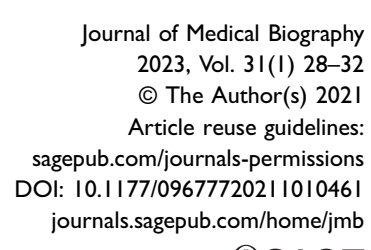

(S)AGE

\author{
Curtis E Margo ${ }^{1,2}$ (1) and Lynn E Harman²
}

\begin{abstract}
The 17th and 18th centuries witnessed an intellectual movement known as the Enlightenment that made possible future revolutions such as the scientific. No person better characterizes the Enlightenment than Voltaire (1696-1976) who, in his book Philosophical Letters published in 1734, venerated the liberalism of English institutions while criticizing the ancien régime of France. He was convinced that the personal freedom the English enjoyed was responsible for their country's success, pointing to inoculation for smallpox and advances in science as evidence. His choice of smallpox inoculation and science as exemplars of empiricism, which maintained that knowledge is obtained through sensory experience, is revealing as it pinpoints political flashpoints that persist to this day. This paper explores how inoculation and science were employed by Voltaire to advance his political idea of liberty.
\end{abstract}

\section{Keywords}

Anti-vaxxer, inoculation, Philosophical Letters, science deniers, smallpox, vaccination, Voltaire

Since the birth of modern science in the middle of the 16th century, there has been a trend to separate scientific and political discourse. As medicine aligned with science by adopting experimental methods of reasoning, it began to distance itself from superstition and politics. Although medicine and science may want to function outside the sphere of politics, such a desire is unrealistic. No person is more associated with intellectual movement known as the Enlightenment as Voltaire (1696-1778), who early in his career found the social tension between science and politics ripe for commentary. In his Philosophical Letters, published initially under a pseudonym in 1734 , he discusses the roles that smallpox inoculation and natural philosophy (science) have on the concept of liberty, a topic still relevant today. ${ }^{1}$

\section{Early modern perspective of epidemics}

Before the causes of plagues were known, deadly contagious diseases sowed civil unrest through the propagation of harmful misconceptions and scapegoating. ${ }^{2}$ Once people realized that they had the power to affect the outcome of epidemics, it created new grounds for social discord. In North America, the controversy over smallpox inoculation in 1721 is a prime example. ${ }^{3}$

Because the American colonies had been repeatedly ravaged by smallpox, they were vigilant in identifying and isolating suspected travelers with the disease. When authorities in Massachusetts discovered a sailor with skin pox in May 1721, they quarantined the man under guard.

\footnotetext{
'Department of Pathology and Cell Biology, Morsani College of Medicine, University of South Florida, Tampa, USA

${ }^{2}$ Department of Ophthalmology, Morsani College of Medicine, University of South Florida, Tampa, USA

Corresponding author:

Curtis E Margo, I 3330 USF Laurel Dr. Morsani Building,

Dermatopathology, 4th Floor, Tampa, FL 336I2, USA.

Email: cmargo@usf.edu
} 